\title{
Inclusion-body myositis: a difficult diagnosis?
}

\author{
Miosite por corpos de inclusão: um diagnóstico difícil?
}

Carolina da Cunha Correia ${ }^{1}$; Maria Clara de Oliveira Magalhães ${ }^{2}$; Pedro Lucas de Mendonça Barbosa ${ }^{2}$; Eliene Dutra Campos ${ }^{3}$; Edmar Zanoteli ${ }^{4}$

\begin{abstract}
Sporadic inclusion-body myositis (IBM) is the most common myopathy in individuals over 55 years of age. However, in many cases, the diagnosis is neglected. Its main findings include progressive muscle weakness, normal or low levels of serum creatine kinase, and the absence of a response to immunosuppression. Muscle biopsy shows inflammatory reaction in association with degenerative changes of the muscle fibers. We report a typical case of IBM, in which diagnosis was possible only after three muscle biopsies. The challenges to confirm histological diagnosis and the caution to avoid repeating tests are discussed.
\end{abstract}

Key words: skeletal muscle; myositis; muscular diseases; biopsy; muscle weakness.

\section{INTRODUCTION}

Idiopathic inflammatory myositis is a group of acquired and heterogeneous muscle illnesses characterized by muscular inflammation. The main forms include polymyositis, dermatomyositis, necrotizing myopathies, and sporadic inclusion-body myositis (IBM) ${ }^{(9)}$. IBM is a late-onset form of myopathy, and it is considered the most common form of myopathy in patients over 55 years of age, with a prevalence of 3.5 in 100 thousand individuals and a male/female ratio of $3: 1^{(9)}$. Clinically, the disease predominantly affects the quadriceps and the gastrocnemius muscles in the lower limbs, and the finger flexors in the upper limbs. The bulbar and cervical musculatures are also affected. Gait impairment usually occurs after 10 to 15 years ${ }^{(3)}$. The histological alterations observed in the muscle biopsy of patients with IBM include two processes that occur side by side: muscle inflammatory reaction and degenerative changes of muscle fibers ${ }^{(2,5,7,9)}$. Typically, there is an inflammatory process invading muscle fibers, and the presence of lymphocytes with positive staining for cluster of differentiation 4 (CD4) and CD8.
On the other hand, there are characteristic neurodegenerative alterations that include the presence of rimmed vacuoles, intracytoplasmic inclusions formed by the accumulation of abnormal proteins, $\beta$-amyloid deposits, and mitochondrial changes ${ }^{(5,7,9)}$. Such degenerative alterations suggest that the disease is actually a form of muscular degeneration with a secondary inflammatory process. This would explain the absence of a response to immunosuppressive therapy ${ }^{(1,4)}$. Due to its slow progression and unspecific results in blood tests, diagnosis is frequently delayed, and in many cases, the main initial diagnoses include polymyositis or neurogenic disorders, such as peripheral neuropathy or motor neuron diseases.

Here we present a typical case of IBM and discuss the challenges in confirming histological diagnosis.

\section{CASE REPORT}

A 68-year-old male complained of slowly progressive muscular weakness persisting for eight years. The symptoms began in the

First submission on 13/06/14; last submission on 21/08/14; accepted for publication on 27/08/14; published on 20/10/14

1. MD from Universidade de Pernambuco (UPE); PhD in Tropical Medicine from Universidade Federal de Pernambuco (UFPE); neurologist at UPE.

2. Medical student at the Medical School of UPE.

3. Biologist at the Department of Neurology, Medical School of Universidade de São Paulo (USP)

4. MD from Universidade Federal do Espírito Santo (UFES); PhD in Neurology from Universidade Federal de São Paulo (UNIFESP); associate professor of Neurology at the

Department of Neurology, Medical School of USP. 
lower limbs, with later involvement of the upper limbs (Figure 1). Other complaints included dysphagia and muscular fatigue. Upon clinical examination, the patient presented with a diffuse muscular atrophy and the inability to stand up without assistance. Sensory examination was normal. There was inconspicuous scoliosis and atrophy of the scapular muscles. Muscle strength testing showed a Medical Research Council (MRC) grade 2 for extension of the legs, flexion of the thighs, and flexion/extension of the wrist; grade 3 for dorsal/plantar flexion of the foot, adduction of the arms, and extension/flexion of the forearm; grade 4 for abduction of the arm; and grade 5 for cervical muscles.

The electromyographic exam showed a myopathic pattern, and the nerve conduction exam was normal. The serum creatine kinase (CK) level was $270 \mathrm{U} / 1$ (the normal value of which is up to 190), and the aldolase level was $7.3 \mathrm{U} / 1$ (the normal value of which is up to 7). Serology testing for human T lymphotropic virus (HTLV), antinuclear factor (ANF), anti-Ro antibody (antiSSA), and anti-La antibody (anti-SSB) was negative.

Two previous muscle biopsies carried out in the biceps brachialis were inconclusive (no images of the slides are available). The previous use of corticoid had shown no clinical improvement. A new muscle biopsy was done on the left deltoid when the patient was 68 years old, and the final histological diagnosis was IBM (Figure 2). Therapy with monthly human immunoglobulin at a dose of $0.4 \mathrm{~g} / \mathrm{kg} /$ day for six months was proposed; however, no clinical improvement was obtained.

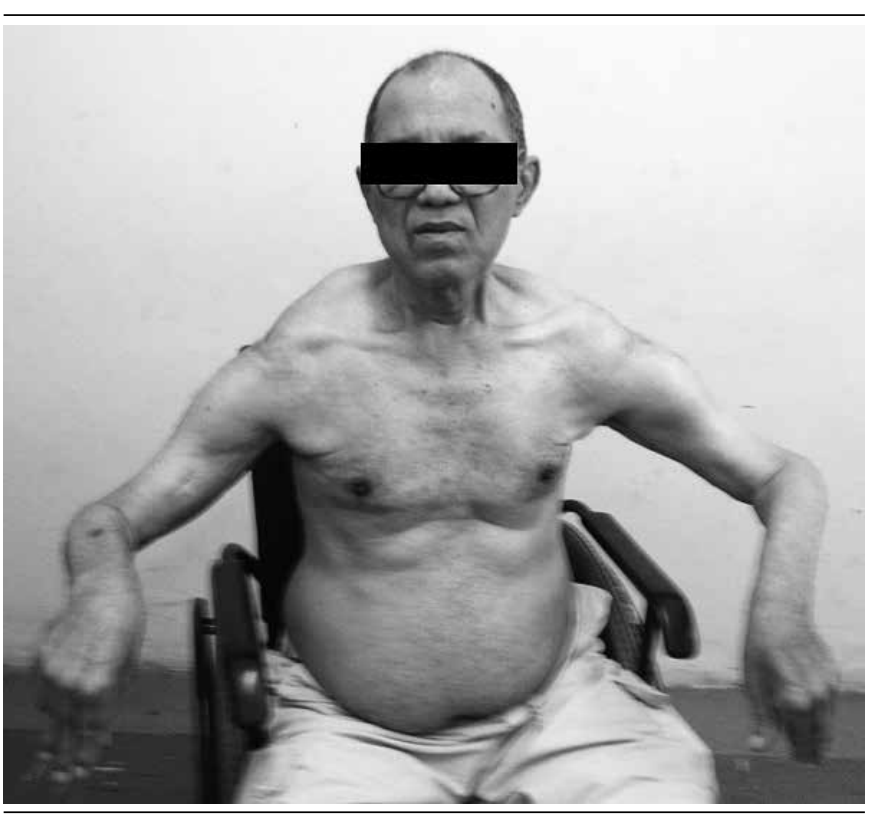

FIGURE 1 -Marked muscle atrophy in the upper limbs in a patient with IBM IBM: inclusion-body myositis.

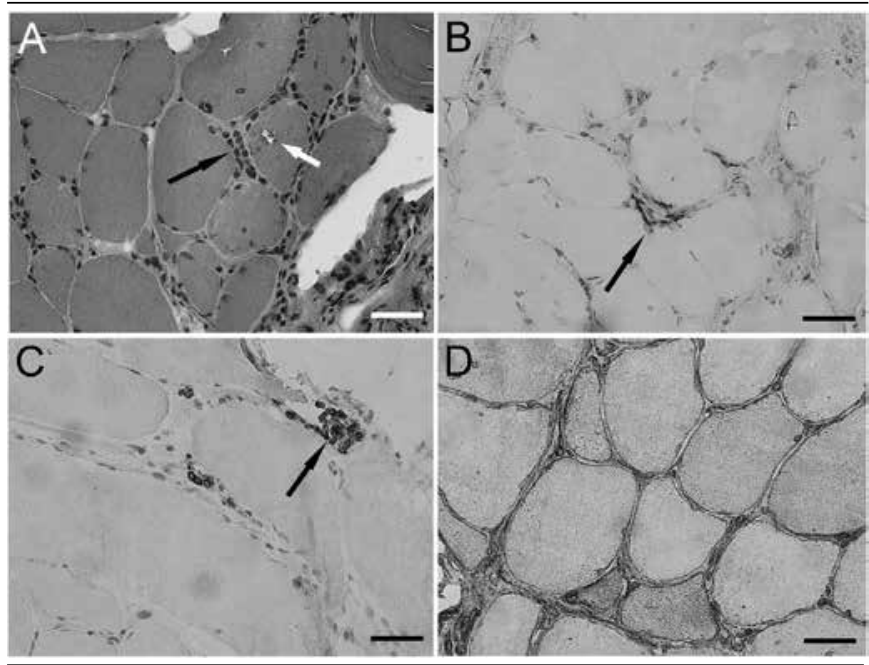

FIGURE 2 -Deltoid muscle biopsy: A) hematoxylin and eosin staining showing endomysial inflammatory reaction (black arrow) besides muscle fibers with rimmed vacuoles (wbite arrow). The peroxidase-IH reaction demonstrated an increase of staining for inflammatory markers CD68 (to identify macrophages) (arrow); B) and CD8 (to identify CD8-lymphocytes) (arrow); C) and diffuse increased expression of the major bistocompatibility complex class I; D) lens $=40 \times$; bars $=50 \mu \mathrm{m}$

IH: immunohistochemical.

\section{DISCUSSION}

Here we presented a patient with clinical and histological features of IBM. IBM is the most common form of myopathy in individuals over 55 years of age, and it presents clinical features that help to suggest diagnosis ${ }^{(8)}$. However, in most situations, as noted in our case, diagnosis is delayed and difficult, even after repeated muscle biopsies.

Diagnostic difficulty occurs because the disease has a very slow course, and the majority of the ancillary exams are inconclusive. For example, CK levels can be normal or only slightly elevated. Antinuclear antibodies are usually absent. The electromyography and nerve conduction tests can show different types of abnormalities, including a typical myopathic pattern, neurogenic alterations with a slight reduction in nerve conduction velocity, or even a mixed pattern ${ }^{(4,6)}$. However, the major problem for diagnosis arises from the inconclusive histological findings in muscle biopsy. This occurs for various reasons.

Firstly, because the disease preferentially affects the quadriceps muscle, biopsies carried out on the upper limbs, especially in the initial stages of the disease, can be inconclusive, showing only unspecific findings. In our case, it was possible to confirm the diagnosis even with a biopsy performed on an upper limb muscle, as, according to the clinical examination, the biceps braquialis was already moderately compromised. In more advanced stages 
of the disease, muscle biopsy in strongly affected muscles, such as quadriceps, may result in the removal of material with great amount of fibrosis or fatty tissue, leading to an inconclusive analysis. Thus, in some cases, the use of magnetic resonance of muscles can help in deciding the best muscle to be biopsied, namely a muscle that is not normal but which is not strongly compromised ${ }^{(8)}$.

Secondly, special techniques for the processing of skeletal muscle, such as histochemical reactions, require frozen material. The freezing process of the muscle is usually done using isopentane cooled in liquid nitrogen, a critical step to avoid freezing artifacts, which can hinder histological analysis. Formaldehyde-fixed paraffin-processed muscle fragments are of little utility for diagnosing IBM, as the characteristic degenerative changes of muscle fibers are not easily recognized. However, it is at least possible to use paraffin blocks to perform immunohistochemical (IH) analysis of inflammatory markers.

Finally, even in the most advanced stages of the disease, degenerative changes, such as rimmed vacuoles, protein aggregates, and mitochondrial alterations, are not always detected, especially when small muscle fragments are analyzed or when clinically very weak muscles are inadequately selected for biopsy ${ }^{(8)}$. In addition, the most characteristic finding - rimmed vacuoles - are noted in only $20 \%$ of muscle biopsies ${ }^{(7,8)}$.

On the other hand, some clinical and laboratorial features can suggest the diagnosis of IBM. Age over 50 years; slowly progressive weakness involving preferentially quadriceps, gastrocnemius, and finger flexors; slight changes in the CK levels; and most importantly, absence of a response to an immunosuppressive therapy, are the major indicators of the disease ${ }^{(2,8,9)}$. The patient presented in this work illustrates part of these difficulties and shows that in some cases, a repetition of muscle biopsy may be necessary to confirm diagnosis.

\section{CONCLUSION}

Muscle biopsy is important to confirm the diagnosis of IBM; however, caution must be exercised regarding its indication in order to avoid the need to repeat tests.

\section{RESUMO}

A miosite por corpos de inclusão (MCI) esporádica é a miopatia mais comum acima dos 55 anos de idade. No entanto, em muitos casos, o diagnóstico é negligenciado. Os principais achados incluem fraqueza muscular progressiva, níveis séricos normais ou levemente elevados de creatinoquinase (CK) e ausência de resposta à imunossupressão. A biópsia muscular evidencia reação inflamatória associada com alterações degenerativas das fibras musculares. Apresentamos um caso típico de MCI cujo diagnóstico foi obtido após a realização de uma terceira biopsia muscular. Discutimos os desafiospara a confirmação do diagnóstico histológico e os cuidados que podem evitar repetições do exame.

Unitermos: músculo esquelético; miopatia inflamatória; doenças musculares; biópsia; fraqueza muscular.

\section{REFERENCES}

1. AGGARWAL, R.; ODDIS, C. V. Therapeutic advances in myositis. Curr Opin Rheumatol, v. 24, n. 6, p. 635-41, 2012.

2. AMATO, A. A.; BAROHN, R. J. Inclusion body myositis: old and new concepts. J Neurol Neurosurg Psychiatry, v. 80, n. 11, p. 1186-93, 2009.

3. BENVENISTE, O. et al. Long-term observational study of sporadic inclusion body myositis. Brain, v. 134, n. 11, p. 3176-84, 2011.

4. CASTRO, C.; GOURLEY, M. Diagnosis and treatment of inflammatory myopathy: issues and management. Ther Adv Musculoskelet Dis, v. 4, n. 2, p. 111-20, 2012.
5. GRIGGS, R. C. et al. Inclusion body myositis and myopathies. Ann Neurol, v. 38, n. 5, p. 705-13, 1995.

6. GUTIÉRREZ-GUTIÉRREZ, G. et al. Use of electromyography in the diagnosis of inflammatory myopathies. Reumatol Clin, v. 8, n. 4, p. 195200, 2012.

7. MACHADO, P. et al. Update in inclusion body myositis. Curr Opin Rheumatol, v. 25, n. 6, 763-71, 2013.

8. ROSE, M. R.; ENMC IBM Working Group. $188^{\text {th }}$ ENMC International Workshop: inclusion body myositis, 2-4 December 2011, Naarden, The Netherlands. Neuromuscul Disord, v. 23, n. 12, p. 1044-55, 2013.

9. VAN DER KOOI, A. J.; DE VISSER, M. Idiopathic inflammatory myopathies. Handb Clin Neurol, v. 119, p. 495-512, 2014.

\section{MAILING ADDRESS}

Carolina da Cunha Correia

Serviço de Neurologia e Neuropediatria; Hospital Universitário Oswaldo Cruz; Rua Arnóbio Marques, 310; Santo Amaro; CEP: 50100-130; Recife-PE, Brazil; Phone: +55 (81) 2101-1357; e-mail: carolina.dra@gmail.com. 